this is all being followed with "watchful interest." SHEA members with news about similar developments in their locales are encouraged to share information with the membership, through the Newsletter.$E d$.

\section{SHEA/CDC Training Program for Hospital Epidemiologists}

When: March 29-31, 1989 (immediately preceding the Centers for Disease Control's annual Epidemic Intelligence Service conference).

Where: Centers for Disease Control, Atlanta, Georgia.

Chairpersons: Allen Kaiser, MD; William Martone, MD; Donald Goldmann, MD.

This program, developed by SHEA and the CIDC, is intended for infectious diseases fellows and new hospital epidemiologists. It emphasizes hands-on exercises in which participants work in small groups to detect, investigate, and control epidemiologic problems encountered in the hospital setting. These working sessions are supplemented with lectures and seminars covering fundamental aspects of hospital epïdemiology.

There is no course fee; however, five awards of $\$ 1,000$ each are available for infectious diseases fellows to defray expenses for travel and accommodations. Interested fellows must submit a letter of not more than one page describing why they want additional training in hospital epidemiology. A letter from the fellow's program director outlining the applicant's qualifications and suitability for the SHEA/ CIDC course is also required. The SHEA Educational Activities Committee will select scholarship recipients based on these letters. Awards are made possible by a grant from Merck, Sharp and Dohme.

Enrollment is limited to 30 persons. Please send scholarship applications, as well as requests for enrollment and additional information to: Allen Kaiser, MD, Vice Chairman, Department of Medicine, Vanderbilt University Medical Center, $\Gamma 3108 \mathrm{MCN}$, Nashville, 'TN 37232; telephone: (615) 343-6821.

\section{Liaison Report-CDC}

William Martone, MD reported that a draft of the CDC year 2,000 objectives was mailed to various organizations for review. He also reported that the National Nosocomial Infection Study (NNIS) has begun collecting risk factor denominator data so that it can determine and report risk-factorspecific infection rates. Dr. Martone reported that NNIS also is increasing the number of participating hospitals (currently about 80). He noted that the Hospital Infections Branch is increasing AIDS funding and will be contracting with several hospitals to study the epidemiology of emergency room exposures to blood and body fluids.

\section{Final Call for Abstracts for SHEA/IC\&HE National Meeting}

Baltimore! March? It will be outstanding! SHEA and ICEHE are cosponsoring a conference entitled, "Hospital Epidemiology: New Challenges and Controversies." It is SHEA's first venture into the national meeting scene and should be a terrific offering. The presenters and discussants include many of our members and well-known experts on topics to be discussed (not mutually exclusive). A registration brochure is enclosed with this issue of the journal. However, in order for us to have a successful meeting, we need your help. We need you to come, attend the sessions, and join the discussion; you may consider presenting a poster if you want to participate more actively. The deadline for abstracts is Jan 31, 1989. An abstract form for the poster session appears on the facing page. For additional registration information, please write to: Hospital Epidemiology: New Challenges and Controversies, 6900 Grove Road, Thorofare, N ew Jersey 08086-9447.
Update on J oint Commission's Hospitalwide Clinical Indicators Task Force

Seventeen pilot hospital sites hav provided preliminary data on the indicators developed by the Joint Commission's task forces on anesthesia and on obstetrics (see March 1988 Newsletter). Now that this data is available, the work of the Joint Commission's Hospital-wide Clinical Indicator's Task Force will be reactivated. Thirteen indicators have been divided into five groups for further evaluation: unplanned admissions, pressure ulcers, infectious diseases, medication errors, and mortality.

SHEA's Severity of IIIness Working Group has consulted with the Joint Commission and provided comments and suggestions on several of the 13 hospital-wide indicators. The working group would be delighted to get input from anyone who has an organized program for collecting and evaluating data on the appropriateness of antibiotic use or a program for monitoring antibiotic side effects. Please contact Peter Gross, MD, chairman, Severity of IIIness Working Group.

\section{SHEA Associates-The Cost-Effective Approach}

SHEA encourages infectious dir ease fellows to join its ranks and receive the journal as Associate Members. Infectious disease fellows wishing to take advantage of this broad spectruni. nontoxic, cost-effective membership category should contact SHEA secretary, Timothy Townsend, MD, Brady, 119, Johns Hopkins Hospital, $600 \mathrm{~N}$. Wolfe St., Baltimore, MD 21205.

Brief items of interest for the SHEA Newslette: mav be sent to Robert A. Weinstein, MD, SHEA Neweletter Editor, Division of Infectious Dis= eases, Michael Reese Hospital, Lake Shore. Drive at 31st St., Chicago, IL 60616. Copy must be typed, double-spaced, and may no. exceed five pages. 